TITLE:

\title{
Preparation of Cationized Polysaccharides as Gene Transfection Carrier for Bone Marrow-Derived Mesenchymal Stem Cells
}

\section{$\operatorname{AUTHOR(S):~}$}

Jo, Jun-ichiro; Okazaki, Arimichi; Nagane, Kentaro; Yamamoto, Masaya; Tabata, Yasuhiko

\section{CITATION:}

Jo, Jun-ichiro ... [et al]. Preparation of Cationized Polysaccharides as Gene Transfection Carrier for Bone Marrow-Derived Mesenchymal Stem Cells. Journal of Biomaterials

Science, Polymer Edition 2010, 21(2): 185-204

\section{ISSUE DATE:}

2010

URL:

http://hdl.handle.net/2433/148425

RIGHT:

(c) Koninklijke Brill NV, Leiden, 2010 


\title{
Preparation of Cationized Polysaccharides as Gene Transfection Carrier for Bone Marrow-Derived Mesenchymal Stem Cells
}

\author{
Jun-ichiro Jo ${ }^{\text {a }}$, Arimichi Okazaki ${ }^{\text {a }}$, Kentaro Nagane ${ }^{\text {a }}$, Masaya Yamamoto ${ }^{a, b}$ \\ and Yasuhiko Tabata ${ }^{\mathrm{a}, *}$ \\ ${ }^{a}$ Department of Biomaterials, Institute for Frontier Medical Sciences, Kyoto University, \\ 53 Kawara-cho Shogoin, Sakyo-ku, Kyoto 606-8507, Japan \\ ${ }^{\mathrm{b}}$ PRESTO, JST, 4-1-8 Honcho, Kawaguchi-shi, Saitama 332-0012, Japan
}

Received 7 December 2008; accepted 19 January 2009

\begin{abstract}
The objective of this study is to prepare a non-viral carrier of gene transfection from various polysaccharides and evaluate the feasibility in gene expression for mesenchymal stem cells (MSCs). Various amounts of spermine were chemically introduced into pullulan, dextran and mannan with a molecular weight of around 40000 or pullulan with different molecular weights to prepare cationized polysaccharides with different extents of spermine introduced (spermine-polysaccharide). Each cationized polysaccharide was complexed with a plasmid DNA at various ratios and in vitro gene transfection was investigated for rat bone marrow-derived MSCs. The level of gene expression depended on the type of cationized polysaccharide. The highest level was observed for the complex of spermine-pullulan and plasmid DNA. Additionally, the level also depended on the molecular weight of pullulan and the extent of spermine introduced to pullulan. Suppression of gene expression with chlorpromazine and methyl- $\beta$-cyclodextrin of endocytosis inhibitors demonstrated that the cellular uptake of spermine-pullulan-plasmid DNA complexes was mediated by clathrin- and raft/caveolae-dependent endocytic pathways. The cationized pullulan is a promising non-viral carrier of plasmid DNA for MSCs.
\end{abstract}

(C) Koninklijke Brill NV, Leiden, 2010

\section{Keywords}

Polysaccharide, spermine, cationized extent, mesenchymal stem cells, asialoglycoprotein receptor, gene expression

\footnotetext{
* To whom correspondence should be addressed. Tel.: (81-75) 751-4121; Fax: (81-75) 751-4646; e-mail: yasuhiko@frontier.kyoto-u.ac.jp 


\section{Introduction}

The recent advent of genome sciences has elucidated genetic sequences which are related to the occurrence of diseases and the proliferation and differentiation of cells for tissue repair. On the other hand, with rapid development of cell biology and tissue regeneration medicine, it has been possible to make use of various precursor and stem cells with high potentials of proliferation and differentiation for cell therapy. One of the most promising cells are bone-marrow-derived mesenchymal stem cells (MSCs), which are multipotent adult stem cells readily isolatable from the bone marrow of patients themselves [1,2]. It is well recognized that MSCs can differentiate into not only osteoblasts, chondrocytes, neurons and skeletal muscle cells, but also vascular endothelial cells [3] and cardiomyocytes [4, 5]. However, since often the cells are not powerful therapeutically, it is of prime importance for successful cell therapy to develop a method of genetic cell engineering aiming at efficient activation and manipulation of cellular functions. To achieve this genetic engineering of cells, virus carriers have been mainly used because of the high efficiency of gene transfection [6-12]. However, there are several problems to be resolved for the clinical applications, such as the antigenicity and toxicity of virus itself or the possibility of disease transfection. Therefore, efficient technology and methodology of gene transfection without virus vectors are highly desirable.

Many types of cationized polymers [13] and cationized liposomes [14-16] have been designed, while complexation with them enabled plasmid DNA to neutralize the anionic charge, as well as to reduce the molecular size, which is preferable to enhance the efficiency of plasmid DNA transfection. Although the expression level of plasmid DNA was enhanced by complexation with the cationized carriers, the electrostatic interaction of the positively charged complexes with the cell surface of negative charge is not cell-specific. Therefore, it is necessary to technologically improve the selectivity of complexes for target cells. Several approaches for the cell-specific gene delivery have been investigated by making use of cell-surface receptors [17] (peptide-recognition receptor [8, 18-20] or sugar chainrecognition receptor [21-25]). Generally, the ligand for the receptor is covalently linked to cationized polymers. For example, the liver targeting of a plasmid DNA is achieved through the covalent conjugation of high-molecular-weight polylysine with asialoorosomucoid [26, 27]. Coupling of galactose residues enabled polyethylenimine to selectively deliver genes to hepatocytes via the asialoglycoprotein receptor-mediated pathway [28, 29].

Gene-delivery systems have been investigated by making use of cationized polysaccharides, such as cationized dextran [30-32], schizophyllan [33] and chitosan [34]. Advantages of the polysaccharide-based carrier over other cationized polymers are the presence of hydroxyl groups available for simple chemical modification and the cell internalization possibly accelerated by a sugar-recognition receptor of cell surface.

It is well recognized that the level of gene expression is greatly influenced by the physicochemical properties of cationized polymer carriers for complexation 
including the molecular weight, the percentage of cationized residues introduced to the carrier polymer and the type or the percentage of amine compounds introduced for cationization. To our best knowledge, there is no report where the effect of polysaccharide type on the level of gene expression was systematically investigated. In this study, various polysaccharides, pullulan, dextran and mannan, with a similar molecular weight of around $40 \times 10^{3}$, or pullulan with different molecular weights were cationized by the chemical introduction of spermine to obtain various cationized polysaccharide derivatives with different extents of spermine introduced. A plasmid DNA was complexed with the cationized polysaccharide derivatives in aqueous solution, and the apparent molecular size and zeta potential of the complexes were measured. The effect of the polysaccharide type, the molecular weight and the extent of spermine introduced on the level of gene expression for MSCs, was investigated. Furthermore, we examined the cellular uptake of spermine-pullulanplasmid DNA complexes using endocytosis inhibitors.

\section{Materials and Methods}

\subsection{Materials}

Pullulan with different weight-average molecular weights $\left(5.9 \times 10^{3}, 11.8 \times 10^{3}\right.$, $22.8 \times 10^{3}, 47.3 \times 10^{3}, 112 \times 10^{3}$ and $212 \times 10^{3}$ ) was purchased from Hayashibara Biochemical Laboratories (Okayama, Japan). Dextran and mannan were purchased from Sigma-Aldrich (St. Louis, MO, USA) and Nacalai Tesque (Kyoto, Japan), respectively. When determined by high-performance liquid chromatography (LC-8020 model-II, Tosoh, Tokyo, Japan) using the pullulan with different weightaverage molecular weights as standards, the weight-average molecular weights of dextran and mannnan were $57 \times 10^{3}$ and $36 \times 10^{3}$, respectively. Spermine was purchased from Sigma. Other chemicals were obtained from Nacalai Tesque and used without further purification.

\subsection{Preparation of Cationized Polysaccharide Derivatives}

Spermine was chemically introduced to the hydroxyl groups of polysaccharide by a $\mathrm{N}, \mathrm{N}^{\prime}$-carbonyldiimidazole (CDI) activation method [35]. Briefly, $9.28 \mathrm{mmol}$ spermine and various molar amounts of CDI were added to $50 \mathrm{ml}$ of dehydrated dimethyl sulfoxide containing $50 \mathrm{mg}$ of each polysaccharide (Table 1). The molar ratio of CDI initially added to the hydroxyl groups $(\mathrm{OH})$ of polysaccharide was defined as the $[\mathrm{CDI}] /[\mathrm{OH}]$ ratio.

Following agitation at $35^{\circ} \mathrm{C}$ for $20 \mathrm{~h}$, the reaction mixture was dialyzed against double-distilled water (DDW) for 2 days. The cut-off molecular weights of dialysis membrane used are 3500 (Spectrum Laboratories, Rancho Domiguez, CA, USA) and $(12-16) \times 10^{3}$ (Viskase, Willowbrook, IL, USA) for pullulan with molecular weights of 5900 and $11.8 \times 10^{3}$, and other polysaccharides, respectively. Then, the dialyzed solution was freezed-dried to obtain samples of spermine-introduced 
Table 1.

Preparation and characterization of spermine-introduced polysaccharides

\begin{tabular}{|c|c|c|c|c|c|}
\hline \multirow{2}{*}{$\begin{array}{l}\text { Polysaccharide } \\
M W \times 10^{-3}\end{array}$} & \multicolumn{5}{|c|}{$[\mathrm{CDI}] /[\mathrm{OH}]^{\mathrm{a}}$} \\
\hline & 0.5 & 1 & 1.5 & 3 & 5 \\
\hline \multicolumn{6}{|l|}{ Pullulan } \\
\hline 5.9 & & & $12.9^{\mathrm{b}}$ & & \\
\hline 11.8 & & & 12.3 & & \\
\hline 22.8 & 2.69 & 5.60 & 11.0 & 23.0 & 32.5 \\
\hline 47.3 & 1.07 & 5.95 & 12.3 & 20.4 & 32.9 \\
\hline 112 & 2.19 & 7.35 & 10.7 & 26.3 & 33.1 \\
\hline 212 & & & 9.74 & & \\
\hline \multicolumn{6}{|l|}{ Dextran } \\
\hline 57 & & & 9.51 & & \\
\hline \multicolumn{6}{|l|}{ Mannan } \\
\hline 36 & & & 13.3 & & \\
\hline
\end{tabular}

a Molar ratio of $\mathrm{N}, \mathrm{N}^{\prime}$-carbonyldiimidazole (CDI) initially added to the hydroxyl groups $(\mathrm{OH})$ of polysaccharide.

b Molar percentage of spermine introduced to the hydroxyl groups of polysaccharide.

polysaccharide (spermine-polysaccharide). The spermine introduction was determined from the conventional element analysis and expressed by the molar extent of spermine introduced to the hydroxyl groups of each polysaccharide.

\subsection{Preparation of Plasmid DNA}

The plasmid DNAs used were the pGL3 plasmid coding a firefly luciferase gene (Luciferase Reporter Vectors-pGL3, Promega, Madison, WI, USA) and the pEGFP-N1 plasmid coding enhanced green fluorescent protein (Takara Bio, Shiga, Japan). The plasmid DNA was propagated in Escherichia coli (strain DH5 $\alpha$ ) and purified with the Qiagen plasmid Mega kit (Qiagen K. K., Tokyo, Japan) according to the manufacturers' instructions. Both the yield and purity of plasmid DNA were evaluated by UV spectroscopy (Ultrospec 2000, Pharmacia Biotech, Cambridge, UK). The absorbance ratio at wavelengths of 260 to $280 \mathrm{~nm}$ for plasmid DNA solution was measured to be between 1.8 and 2.0.

\subsection{Preparation of Spermine-Polysaccharide-Plasmid DNA Complexes}

Polyion complexes (PIC) were prepared by mixing an aqueous solution of spermine-polysaccharide with that of plasmid DNA. Briefly, varied amounts of spermine-polysaccharide were dissolved in $50 \mu \mathrm{l}$ DDW and mixed with $50 \mu \mathrm{l}$ $10 \mathrm{mM}$ phosphate-buffered saline solution (PBS, pH 7.4) containing $100 \mu \mathrm{g}$ plasmid DNA, followed by leaving for $15 \mathrm{~min}$ at room temperature to obtain various PIC of spermine-polysaccharide and plasmid DNA. The PIC composition was calculated on the basis of the nitrogen number of spermine-polysaccharide $(\mathrm{N})$ per 
phosphorus number of plasmid DNA (P) and expressed as the N/P ratio. To complex the plasmid DNA with Lipofectamine 2000 (Invitrogen, Carlsbad, CA, USA), $50 \mu \mathrm{l}$ Opti-MEM (Invitrogen) containing $5.0 \mu \mathrm{g}$ Lipofectamine was mixed with $50 \mu \mathrm{l}$ Opti-MEM containing $2.5 \mu \mathrm{g}$ plasmid DNA, followed by leaving for $15 \mathrm{~min}$ at room temperature.

\subsection{Electrophoretic Measurement of Spermine-Polysaccharide-Plasmid DNA Complexes}

PIC were prepared in $10 \mathrm{mM}$ PBS solution at a N/P ratio of 3.0. After $15 \mathrm{~min}$ incubation, $10 \mu \mathrm{l}$ of the complex was added to $3 \mu \mathrm{l}$ of a loading buffer $(0.1 \%$ sodium dodecyl sulfate, $5 \%$ glycerol and $0.005 \%$ bromophenol blue) and applied to an $1 \mathrm{wt} \%$ agarose gel in Tris-borate-ethylenediaminetetraacetic acid buffer solution (TBE, $\mathrm{pH} 8.3$ ) containing $0.1 \mathrm{mg} / \mathrm{ml}$ ethidium bromide (EtBr). Electrophoretic evaluation of the PIC was carried out in TBE solution at $100 \mathrm{~V}$ for $30 \mathrm{~min}$. The gel was imaged with a UV transilluminator (Gel Doc 2000, Bio-Rad Laboratories, Segrate, Italy).

\subsection{Dynamic Light Scattering (DLS) and Electrophoretic Light Scattering (ELS) Measurements}

PIC were prepared in $10 \mathrm{mM}$ PBS solution at a N/P ratio of 3.0. The DLS measurement was carried out using a DLS-DPA-60HD instrument (Otsuka Electronic, Osaka, Japan) equipped with an $\mathrm{Ar}^{+}$laser at a detection angle of $90^{\circ}$ at $25^{\circ} \mathrm{C}$ for $15 \mathrm{~min}$. In the present study, the autocorrelation function of samples was analyzed based on the cumulant method and the $R_{\mathrm{S}}$ value was calculated automatically by the equipped computer software and expressed as the apparent molecular size of samples. On the other hand, the zeta potential was measured using ELS-7000AS instrument (Otsuka Electronic) at $25^{\circ} \mathrm{C}$ and an electric field strength of $100 \mathrm{~V} / \mathrm{cm}$. From the determined electrophoretic mobility, the zeta potential was automatically calculated using the Smoluchowski equation. Light scattering measurement was done three times for every sample.

\subsection{Lectin-Induced Aggregation of Spermine-Polysaccharide-Plasmid DNA Complexes}

PIC were prepared in PBS at a N/P of 3.0, followed by incubation at room temperature for $15 \mathrm{~min}$. To $100 \mu \mathrm{l}$ of the PIC solution, $100 \mu \mathrm{l}$ of Ricinus communis agglutinin of lectin recognizable to galactose (RCA120, Seikagaku, Tokyo, Japan, $500 \mu \mathrm{g} / \mathrm{ml}$ ) was added, followed by incubation at room temperature. The time profile of solution turbidity change was measured at a wavelength of $500 \mathrm{~nm}$. To confirm the specificity of lectin-sugar interaction, D-galactose was added $40 \mathrm{~min}$ after RCA120 addition. The results were expressed as the percentage of the solution absorbance to that of spermine-polysaccharide-plasmid DNA complex alone. 


\subsection{In Vitro Gene Transfection Experiment}

MSC culture was performed according to the method previously described [1]. Briefly, 3-week-old male Wistar rats (Shimizu Laboratory Supplies, Kyoto, Japan) were killed to isolate the femur and tibia, and the bone marrow was harvested by flushing the bone with PBS. The suspension of bone marrow cells in PBS was placed into $25 \mathrm{~cm}^{2}$ cell-culture flasks (Corning, Corning, NY, USA) and cultured in $\alpha$-minimum essential medium ( $\alpha$ MEM) supplemented with 15 vol\% bovine fetal calf serum (FCS, Hyclone Laboratories, Logan, UT, USA) and $1 \mathrm{wt} \%$ mixed penicillin and streptomycin solution (Sigma-Aldrich, control medium). After incubation at $37^{\circ} \mathrm{C}$ in $5 \% \mathrm{CO}_{2}$ and $95 \%$ air at atmospheric pressure for 3 days, non-adherent cells were removed. Adherent cells were further cultured by exchanging the fresh control medium every 3 days. The cells were collected with $0.25 \mathrm{wt} \%$ trypsin-containing $0.8 \mathrm{mM}$ ethylenediaminetetracetic acid solution in PBS, and then subcultured in $225 \mathrm{~cm}^{2}$ cell-culture flasks to allow to grow at $80 \%$ cell confluency for the following transfection experiments.

The transfection experiments were performed independently in triplicate. MSCs were seeded on each well of 12 multi-well cluster plate (Corning) at a density of $5 \times$ $10^{4}$ cells/well and cultivated in $1 \mathrm{ml}$ of control medium for $24 \mathrm{~h}$. Immediately after the medium was exchanged by FCS-free control medium, PIC solution $(100 \mu \mathrm{l})$ was added, followed by $6 \mathrm{~h}$ incubation for cell gene transfection. Then, the medium was changed to the control medium and cells were incubated for another $24 \mathrm{~h}$.

Cells were washed with PBS once, lysed in $200 \mu$ of a cell-culture lysis reagent (Promega, Madison, WI, USA), transferred into a micro reaction tube, and the cell debris was separated by centrifugation $\left(14 \times 10^{3} \mathrm{rpm}, 20 \mathrm{~min}\right)$. Then, $100 \mu \mathrm{l} \mathrm{lu}-$ ciferase assay reagent (Promega) was added to $20 \mu \mathrm{l}$ supernatant, while the relative light unit (RLU) of the samples was determined by a luminometer (MicroLumatPlus LB 96V, Berthold, Tokyo, Japan). The total protein of each well was determined with a bicinchonic acid (BCA) Protein assay kit (Pierce, Rockford, IL, USA) according to the manufacturers' instructions in order to normalize the influence of number variance of cells on the luciferase activity. Each experimental group was carried out three times independently. Chlorpromazine (CPZ, clathrin-mediated endocytosis inhibitor [36, 37], $10 \mu \mathrm{g} / \mathrm{ml}$, Sigma) and methyl- $\beta$-cyclodextrin $(\mathrm{M} \beta \mathrm{CD}$, $\mathrm{raft} /$ caveolae-mediated endocytosis inhibitor [38-40], $10 \mathrm{mM}$, Sigma) were preincubated for $30 \mathrm{~min}$, and then the similar transfection experiment was performed to evaluate the endocytosis pathway of spermine-pullulan-plasmid DNA complexes.

\subsection{Evaluation of Plasmid DNA Internalization}

Plasmid DNA was labeled with rhodamine using the Label IT ${ }^{\circledR}$ Fluorescein isothiocyanate (FITC) Labeling Kit (Mirus ${ }^{\circledR}$, Madison, WI, USA) according to the manufacturers' instructions. After transfection culture for 1 day with the free FITClabeled plasmid DNA or the complex with Lipofectamine $2000^{\circledR}$ or sperminepolysaccharide, the cells were treated in cold acetate-buffered solution containing $0.3 \mathrm{vol} \%$ acetic acid, $0.085 \mathrm{M} \mathrm{NaCl}$ and $5.0 \mathrm{mM} \mathrm{KCl}$ for $1 \mathrm{~min}$, then the cells were 
washed with cold PBS to remove the complexes bound onto the cell surface. The cells of three wells were collected by the trypsinization, and the results were considered as an average value of triplicates, while ten thousand cells were measured by the fluorescence activated cell sorter (FACSCalibur, Becton Dickinson, Franklin Lakes, NJ, USA) with Cell Quest Pro Software. The percentage of FITC-positive cells was calculated by setting the background population as $98 \%$ negative when analyzing control cells [41].

\subsection{Microscopic Observation of Intracellular Localization}

Plasmid DNA was labeled with Cy5 using the Label $\mathrm{IT}^{\circledR}$ Cy5 Labeling Kit (Mirus ${ }^{\circledR}$ ). After the transfection culture for 1 day with the complex of Cy5labeled plasmid DNA and spermine-polysaccharide, cells were washed and fixed with $0.25 \mathrm{wt} \%$ glutaraldehyde solution in PBS, followed by staining nucleus with Hoechst 33342 (Molecular Probes, Eugene, OR, USA). Imaging data of cells were collected on an Olympus Fluoview FV300 confocal laser scanning microscope (Olympus, Tokyo, Japan) and processed with Adobe Photoshop 6.0 software (Adobe Systems, San Jose, CA, USA).

\subsection{Cell Viability}

Cytotoxicity was assayed using a cell counting kit (Nacalai Tesque). Cells were seeded on each well of 96 multi-well cluster plate (Corning) at a density of $1 \times$ $10^{4}$ cells/well and cultivated in the control medium for $24 \mathrm{~h}$. The medium was changed to the fresh FCS-free control medium, and $10 \mu \mathrm{l}$ of the PIC solution was applied to each well, followed by $6 \mathrm{~h}$ incubation. Then, the medium was changed to the control medium and $10 \mu \mathrm{l}$ 2-(2-methoxy-4-nitrophenyl)-3-(4-nitrophenyl)-5(2,4-disulfophenyl)-2H-tetrazolium (WST-8) solution was added and the cells were incubated for another $3 \mathrm{~h}$. The absorbance of samples was measured at $450 \mathrm{~nm}$ by VERSAmax microplate reader (Molecular Devices, Sunnyvale, CA, USA). The percent cell viability was expressed as $100 \%$ for control (non-treated cells).

\subsection{Statistical Analysis}

All the data were expressed as the mean \pm the standard deviation of the mean. Statistical analysis was performed based on the ANOVA, followed by Fisher's PLSD and significance was accepted at $P<0.05$.

\section{Results}

\subsection{Cationization of Polysaccharide}

Spermine was chemically introduced to the hydroxyl groups of polysaccharide by the CDI activation method (Table 1). The extent of spermine introduced could be changed by altering the amount of CDI added initially, and but no big difference in the introduced extent was observed in terms of the type and molecular weight of polysaccharide used. 


\subsection{Characterization of Spermine-Polysaccharide-Plasmid DNA Complexes}

To confirm the formation of polyion complexes and characterize their physicochemical properties, electrophoresis analysis, DLS and ELS measurement were performed.

Figure 1 shows the electrophoretic patterns of polyion complexes of plasmid DNA and spermine-polysaccharide prepared at a N/P ratio of 3.0. Migration of plasmid DNA was retarded and became invisible by complexation with speminepolysaccharide.

Table 2 summarizes the physicochemical properties of polyion complexes prepared at a N/P ratio of 3.0. The apparent molecular size and the zeta potential of free plasmid DNA were around $400 \mathrm{~nm}$ and $-15 \mathrm{mV}$, respectively. Irrespective of

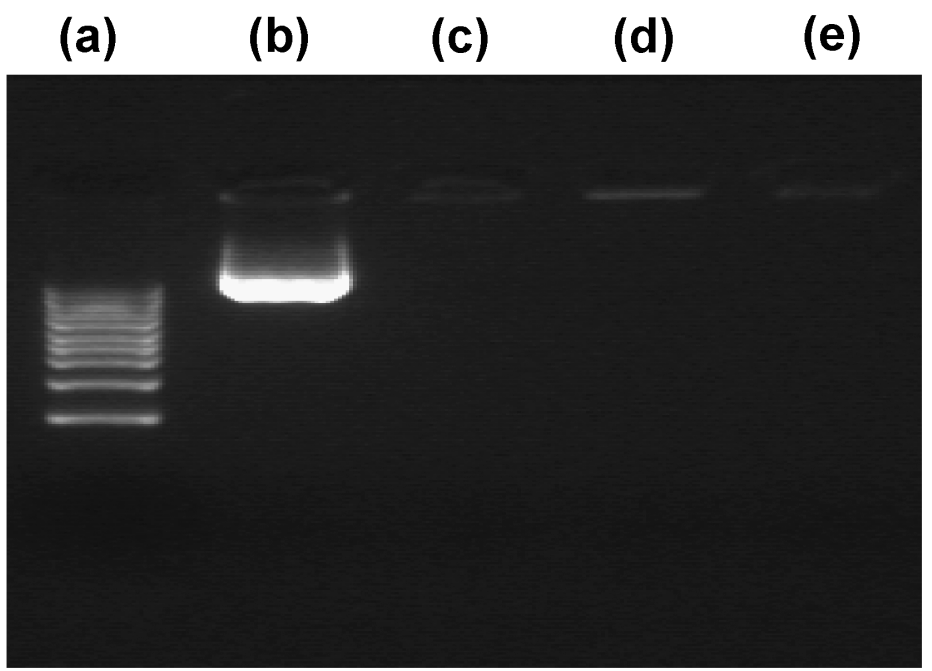

Figure 1. Agarose gel electrophoresis of spermine-polysaccharide-plasmid DNA complexes prepared at a N/P ratio of 3.0. Shown are DNA marker (a), free plasmid DNA (b) or the complexes of plasmid DNA and spermine derivatives of pullulan (c), dextran (d) and mannan (e). The $[\mathrm{CDI}] /[\mathrm{OH}]$ ratio of spermine-polysacccharide used for cationization is 1.5 .

Table 2.

Apparent molecular size and zeta potential of plasmid DNA complexed at a N/P ratio of 3.0 with cationized polysaccharides

\begin{tabular}{llc}
\hline & Apparent molecular size $(\mathrm{nm})$ & Zeta potential $(\mathrm{mV})$ \\
\hline Pullulan & $226.3 \pm 51.9$ & $+12.2 \pm 1.5$ \\
Dextran & $157.0 \pm 28.3$ & $+14.0 \pm 0.1$ \\
Mannan & $293.5 \pm 28.5$ & $+12.0 \pm 0.5$ \\
Free plasmid DNA & $409.5 \pm 61.2$ & $-14.7 \pm 9.5$ \\
\hline
\end{tabular}

Values are means $\pm \mathrm{SD}$. 


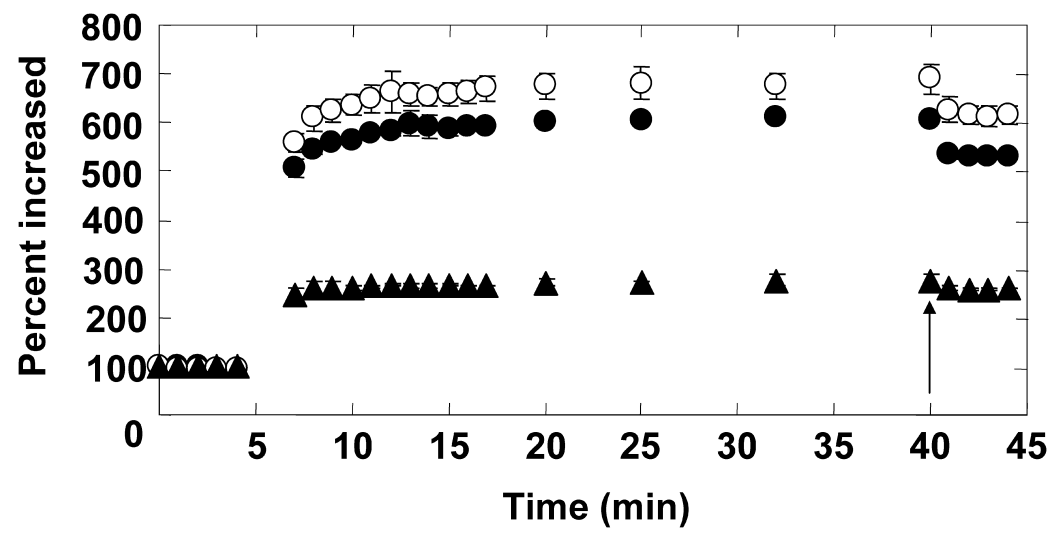

Figure 2. Time-course of the turbidity change of spermine-polysaccharide-plasmid DNA complexes prepared at a N/P ratio of 3 after addition of RCA 120. Galactose was added 40 min after RCA 120 addition (indicated by an arrow). The type of polysaccharide used for spermine introduction is pullulan $(\bigcirc)$, dextran $(\bullet)$ and mannan $(\boldsymbol{\Delta})$. The $[\mathrm{CDI}] /[\mathrm{OH}]$ ratio of spermine-polysacccharide used for cationization is 1.5 .

the polysaccharide type, the apparent molecular size and zeta potential was around $160-280 \mathrm{~nm}$ and $10-16 \mathrm{mV}$, respectively.

In addition to the physicochemical properties of spemine-polysaccharideplasmid DNA complexes, their biological properties, such as sugar-lectin interaction, were investigated.

Figure 2 shows the time-course of solution absorbance change of sperminepolysaccharide-plasmid DNA complexes after the addition of RCA120 lectin. The solution absorbance increased time-dependently, although the increment pattern of depended on the polysaccharide type. When galactose was added to the solution, the absorbance decreased.

\subsection{In Vitro Gene Transfection of Spermine-Polysaccharide-Plasmid DNA Complexes}

The in vitro gene transfection for MSCs was performed by the plasmid DNA complexed with spermine derivatives of different polysaccharides to evaluate the effect of polysaccharide type on the level of gene expression, the cellular internalization efficiency and the intracellular trafficking.

Figure 3 shows the effect of the type of polysaccharides used for spermine introduction on the luciferase expression of spermine-polysaccharide-plasmid DNA complexes at a N/P ratio of 3.0 for MSCs. The level of gene expression by the spermine-pullulan-plasmid DNA complexes was significantly higher than that of free plasmid DNA and the plasmid DNA complexes of Lipofectamine 2000 or the spermine derivatives of other polysaccharides.

Figure 4 shows the fluorescence histogram of MSCs 1 day after transfection with free FITC-labeled plasmid DNA or the complex of Lipofectamine $2000^{\circledR}$ or spermine derivatives of different polysaccharide types. The percentages of plasmid 


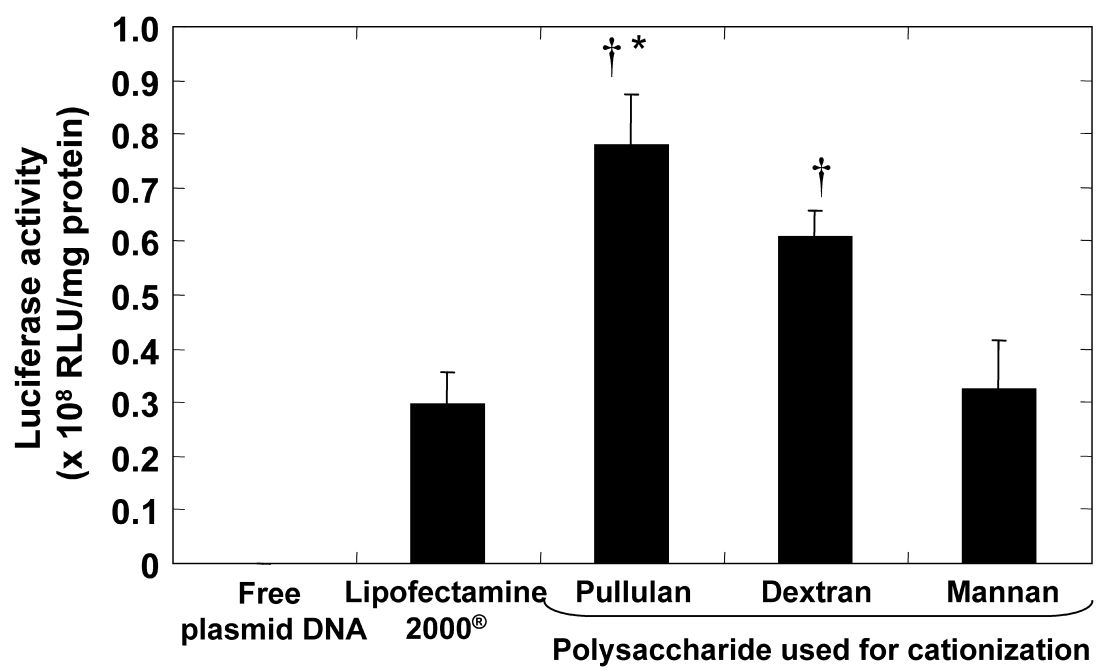

Figure 3. The effect of different polysaccharides for the introduction of luciferase plasmid DNA complex in MSCs. The amount of plasmid DNA applied is $2.5 \mu \mathrm{g} / \mathrm{well}$ and the N/P ratio is 3.0. ${ }^{*} P<0.05$ versus the expression level of complexes prepared by other spermine-polysaccharides. ${ }^{\dagger} P<0.05$ versus the expression level of complexes prepared by Lipofectamine $2000^{\circledR}$.

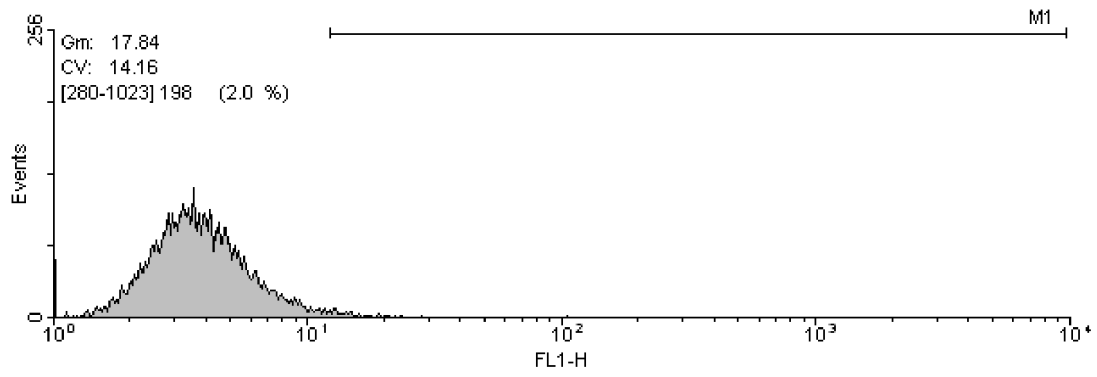

(a)

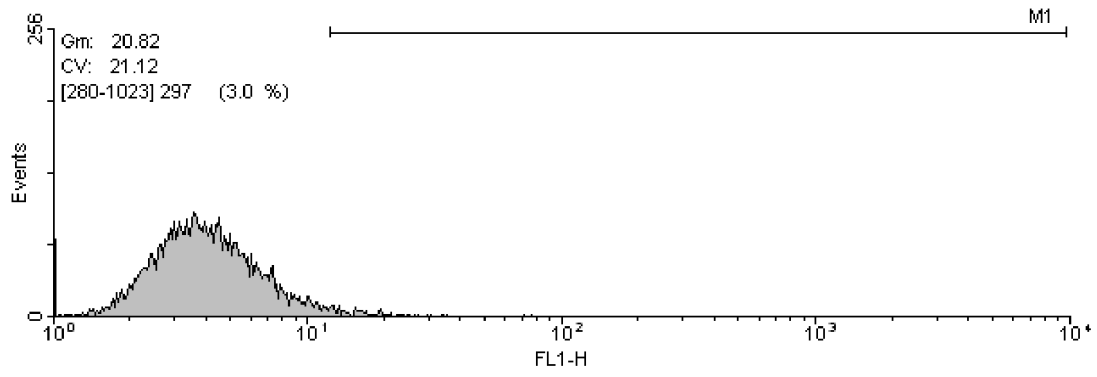

(b)

Figure 4. Fluorescence histogram of MSCs 1 day after non-transfection (a) or transfection with free FITC-labeled plasmid DNA (b) or the complex of Lipofectamine $2000^{\circledR}$ (c) or spermine derivatives of pullulan (d), dextran (e) and mannan (f). The amount of plasmid DNA applied is $2.5 \mu \mathrm{g} / \mathrm{well}$ and the $\mathrm{N} / \mathrm{P}$ ratio is 3.0 . 


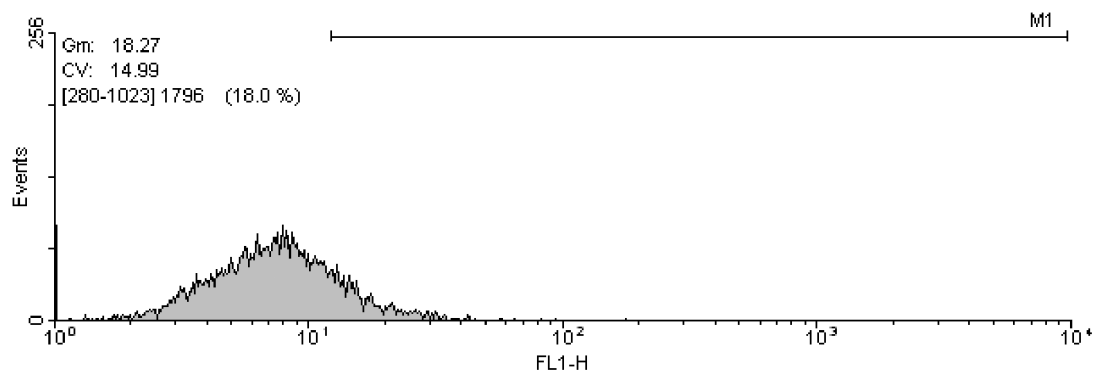

(c)

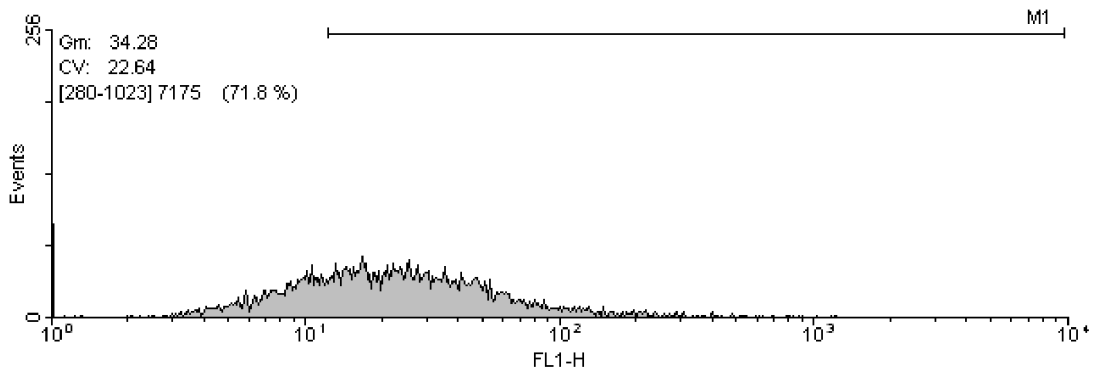

(d)

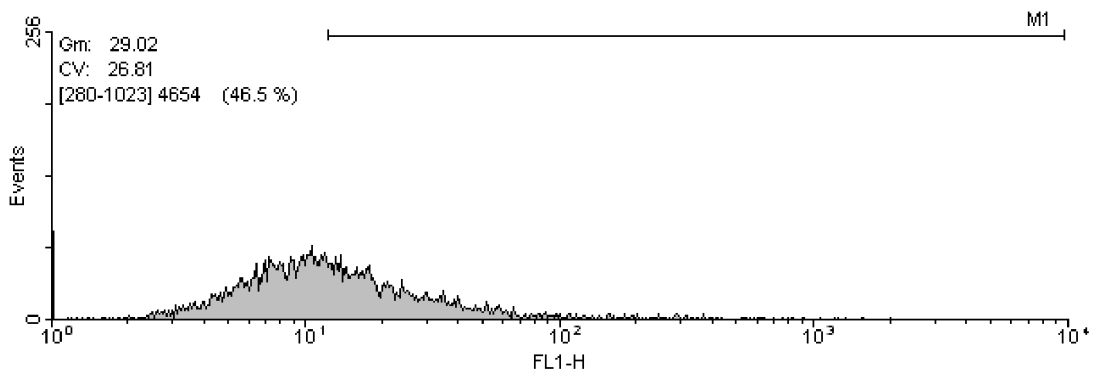

(e)

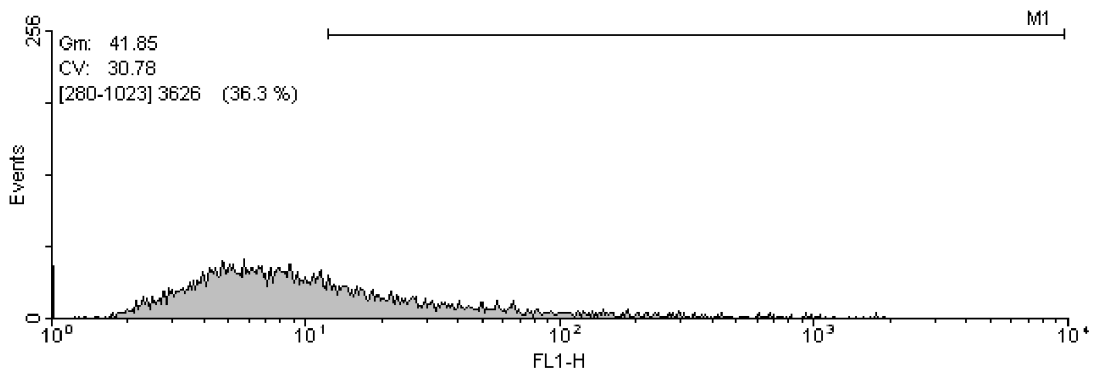

(f)

Figure 4. (Continued.)

DNA internalized were 3.0, 18.0, 71.8, 46.5 or 36.3 for MSCs transfected with free plasmid DNA, the complex of Lipofectamine $2000^{\circledR}$ or spermine derivatives of pullulan, dextran and mannan, respectively. 


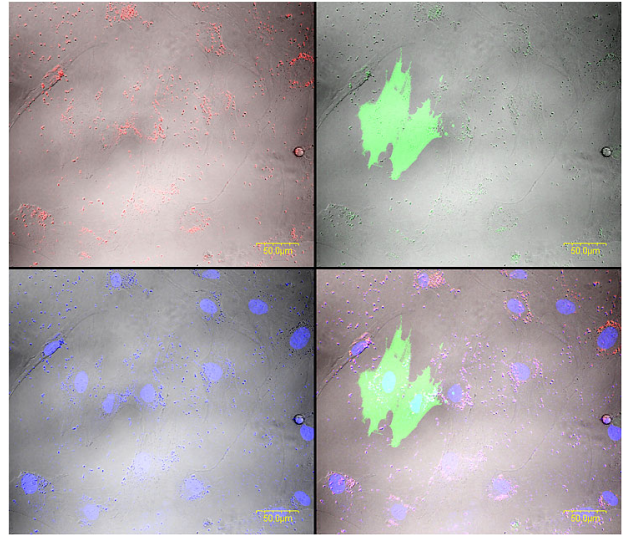

(a)

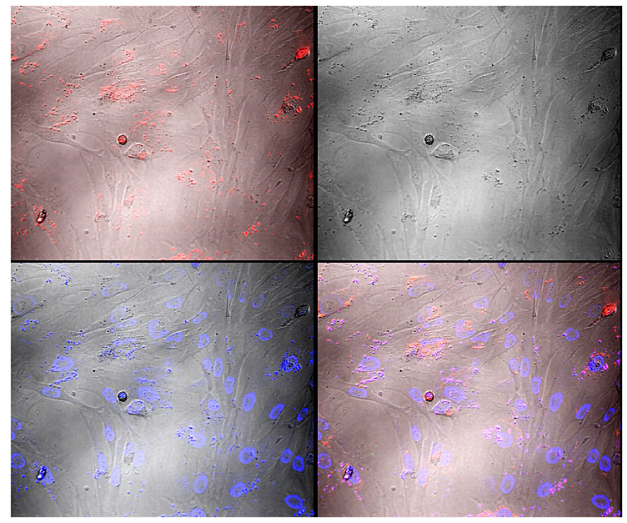

(c)

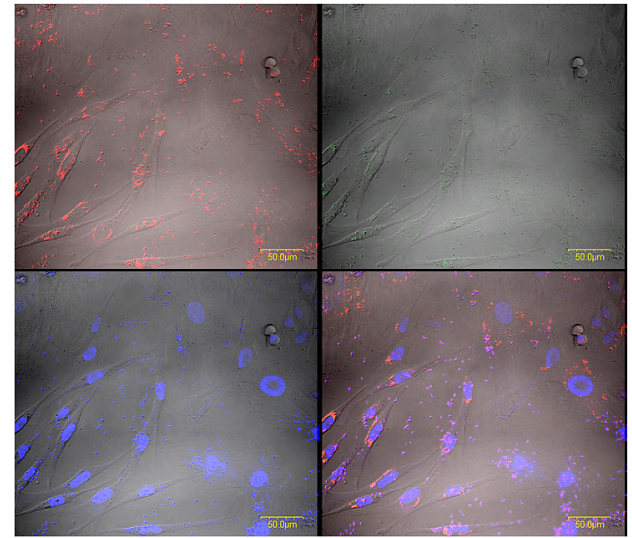

(b)

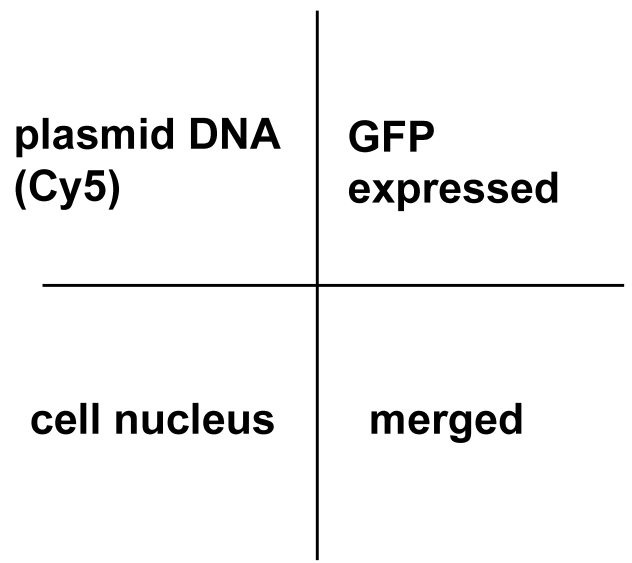

Figure 5. Confocal laser microscopic images of MSCs 1 day after transfection with GFP plasmid DNA complex of spermine derivatives of pullulan (a), dextran (b) and mannan (c). The plasmid DNA was labeled with Cy5. The amount of plasmid DNA used for transfection is $2.5 \mu \mathrm{g}$. The N/P ratio of spermine-polysaccharide-plasmid DNA complex is 3.0. The red, green and blue points indicate the plasmid DNA, GFP expressed and cell nucleus, respectively. This figure is published in the online edition of this journal, that can be accessed via http://www.brill.nl/jbs

Figure 5 shows the confocal laser microscopic images of MSCs 1 day after transfection with spermine-polysaccharide-plasmid DNA complexes. Most of plasmid DNA were localized around or in the nucleus of MSCs. Strong GFP expression was observed in the MSCs transfected with spermine-pullulan-plasmid DNA complexes.

\subsection{MSC Gene Expression with Different Spermine-Pullulan Derivatives}

To optimize the physicochemical condition of spemine-pullulan derivatives for MSC gene expression, the effect of the pullulan molecular weight and the extent of spermine introduced on the luciferase expression of spermine-pullulan-plasmid 


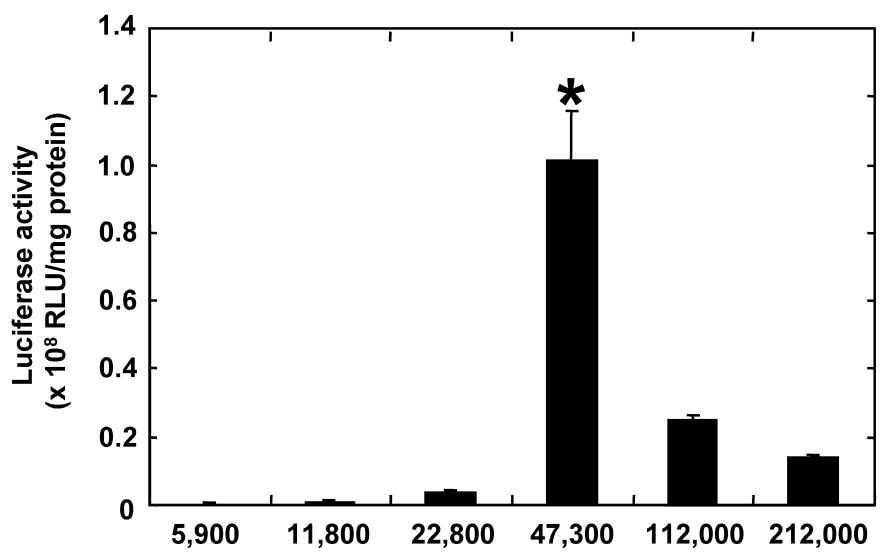

(a)

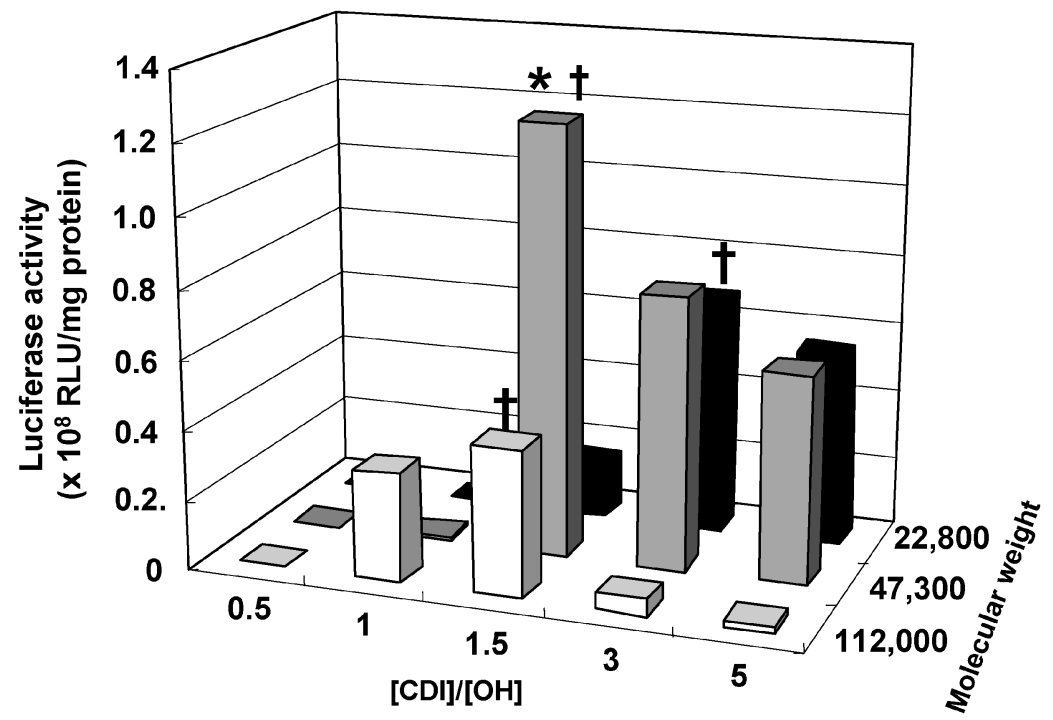

(b)

Figure 6. Effect of the pullulan molecular weight (a) and the extents of spermine introduced to pullulan at the corresponding molecular weight (b) on the luciferase expression of spermine-pullulan-plasmid DNA complexes for MSCs. The amount of plasmid DNA applied is $2.5 \mu \mathrm{g}$ and the N/P ratio is 3.0. ${ }^{*} P<0.05$ versus the expression level of complexes prepared by other spermine-pullulans. ${ }^{\dagger} P<0.05$ versus the expression level of complexes prepared by other spermine derivatives of pullulan at the corresponding molecular weight.

DNA complexes for MSCs was investigated. The highest level was observed for the complex of spermine derivative of pullulan with the molecular weight of 47300 (Fig. 6A). On the other hand, the level of gene expression depended on the type of spermine-pullulan derivatives with different percentages of spermine introduced. The extent of spermine introduced where the highest level was observed depended on the molecular weight of the pullulan used for spermine introduction (Fig. 6B). 


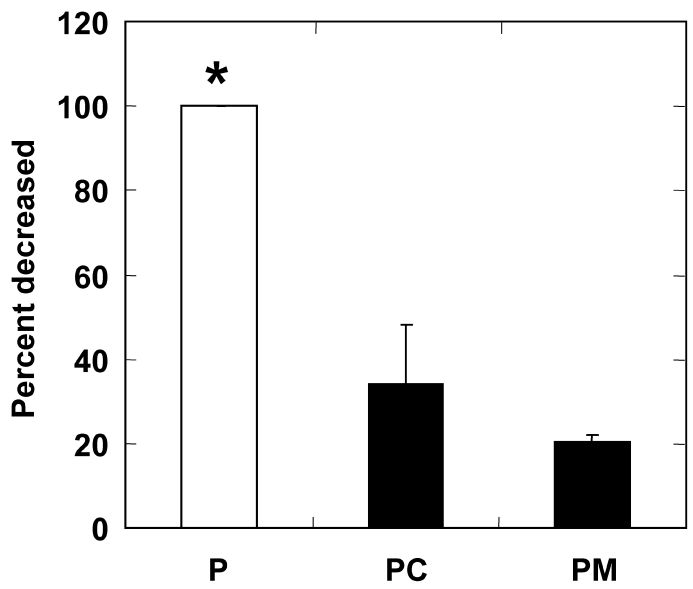

Figure 7. Effect of endocytosis inhibitors on the level of luciferase expression of spermine-pullulan-plasmid DNA complexes prepared at the N/P ratio of 3.0 for MSCs. Cells were pretreated with chloropromazine (PC) or methyl- $\beta$-cyclodextrin (PM) (solid columns) or without (open column, $\mathrm{P}$ ) endocytosis inhibitors before gene transfection. The plasmid DNA amount is $2.5 \mu \mathrm{g}$. The molecular weight of pullulan used for spermine introduction is $47.3 \times 10^{3} .{ }^{*} P<0.05$ versus the expression level of cells transfected with the addition of endocytosis inhibitors.

To clarify the cellular uptake mechanism of spermine-pullulan-plasmid DNA complexes, an inhibition test was performed.

Figure 7 shows the effect of endocytosis inhibitors on the level of luciferase expression of spermine-pullulan-plasmid DNA complexes prepared at the N/P ratio of 3.0 for MSCs. The gene expression level was decreased by pre-treatment with both endocytosis inhibitors, $\mathrm{CPZ}$ and $\mathrm{M} \beta \mathrm{CD}$.

\subsection{Cytotoxicity of Spermine-Pullulan-Plasmid DNA Complexes}

Figure 8 shows the viability of cells $3 \mathrm{~h}$ after exposure of PIC prepared at a N/P ratio of 3.0. The cell viability decreased with the increased amount of plasmid DNA added. However, less cytotoxicity was observed for the complex at $0.25 \mu \mathrm{g} / \mathrm{ml}$, the concentration at which the cell transfection experiment was performed.

\section{Discussion}

It has been demonstrated that cells themselves have good therapeutic potentials in terms of their inherent targetability to the injury site and biological properties of specific tissue [42-44]. However, the therapeutic efficacy of cells transplanted is not always as high as expected, which is one of the largest problems in cell therapy. This is because the grafting rate of cells transplanted is low and consequently the biological functions of cells become low in the body. To tackle the problems, it is indispensable to develop materials, technologies and methodologies to provide the cells a local environment where the survival and biological functions of cells transplanted can be maintained or enhanced. One of the most effective technologies is 


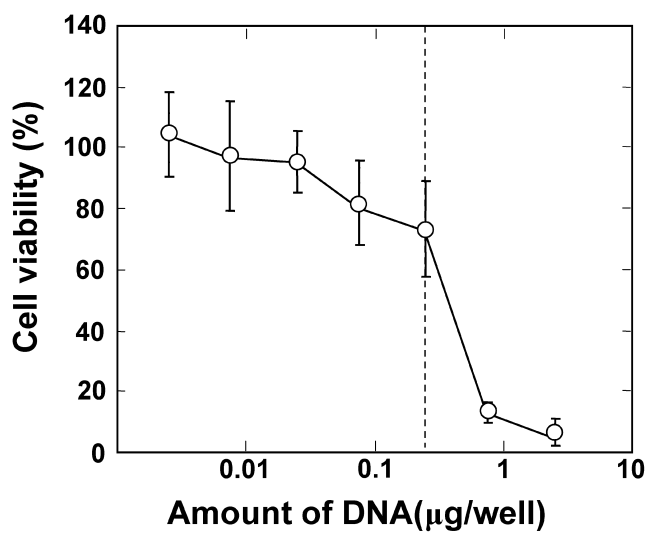

Figure 8. Effect of the plasmid DNA amount on the viability of MSCs transfected with spermine-pullulan-plasmid DNA complexes prepared at a N/P ratio of 3.0. The molecular weight of pullulan used for spermine introduction is $47.3 \times 10^{3}$. The viability of cells without transfection is indicated as $100 \%$. The dotted line indicates the amounts of plasmid DNA used for the gene transfection test.

genetic engineering. Genetic engineering is effective in not only artificially modifying the biological functions of cells, such as proliferation, differentiation, and therapeutic abilities applicable to cell therapy [10,45-51], but also developing the basic research of cell biology and medicine which is important to identify and investigate genes regulating the biological function of cells. It has been reported that the biological functions of genetically engineered cells are therapeutically superior to those of the original ones $[10,52,53]$.

It is indispensable to develop technology and methodology of gene transfection for genetic engineering of cells. Considering the clinical use, it is necessary to develop a non-viral gene carrier. For efficient gene transfection, it is important to design carriers that can electrostatically bind to a genetic material, molecularly condense the material size to a diameter range of several hundred nanometers, which will facilitate the cell internalization. In addition, it is also necessary to develop a carrier for a cell-specific delivery system, which allows genes to deliver specifically to the target cell and enhance the expression level.

Among the non-viral materials applicable to a gene transfection carrier [54-56], polysaccharide has an advantage over other substances in terms of the ability to be recognized by the respective cell receptors of sugar specificity. This biological recognition not only permits the receptor-specific targeting of substances to the cell, but also accelerates their cell uptake via receptor-mediated endocytosis. Therefore, we investigated the effect of polysaccharide type on the level of gene expression. In this study, spermine was introduced to polysaccharide because spermine is one of the polyamines present in the body, and cationization with spermine converted gelatin to a non-viral carrier of plasmid DNA with a transfection efficiency higher than that with other amine compounds [57]. In the present study, the complex of cationized polysaccharide and plasmid DNA was formed at a N/P 
ratio of 3.0 because it has been previously reported that efficient gene transfection and less cytotoxicity were observed for the complex prepared at the N/P ratio [58].

Dependence of the polysaccharide type on the level of gene expression (Figs 3 and 5) can be explained as follows. The electrophoresis analysis (Fig. 1) and the DLS and ELS measurements (Table 2) revealed that physicochemical properties of plasmid DNA complexes were not changed by the polysaccharide type, although they were changed compared with those of free plasmid DNA. In the electrophoresis analysis, the images of DNA complexed with spermine-polysaccharide became invisible. This is due to the dissociation of EtBr-plasmid DNA complex by the complexation with spermine-polysaccharide, the so-called EtBr exclusion. On the other hand, the lectin affinity assay (Fig. 2) revealed that the plasmid DNA complexes with spermine derivatives of pullulan and dextran were strongly recognized by the sugar-recognizable lectin, RCA120, which has the same recognition site, ASGPR. It is possible that the pullulan and dextran chains present on the complex surface are specifically recognized by the lectin, resulting in the formation of complexlectin aggregates. We have previously found that the ASGPR was expressed in MSC [53]. Several researchers have demonstrated that pullulan of a polysaccharide accumulates in the liver via the ASGPR at significantly higher amounts than other water-soluble polymers [59, 60]. Based on these findings, it is highly suggested that the polysaccharide type affects the cellular internalization of plasmid DNA via ASGPR. It is conceivable that these recognition differences among polysaccharide types contribute the cellular internalization, resulting in enhancing the level of gene expression. This is also supported by the cellular internalization analysis result (Fig. 4).

The highest level of gene expression was observed for the plasmid DNA complex with spermine derivatives of pullulan. Therefore, for the pullulan derivatives, we examine the effect of the molecular weight and the extent of spermine introduced on the level of gene expression to demonstrate the dependence (Fig. 6). A similar tendency of the gene expression level for MSCs was observed for HepG2, a human hepatoma cell line which has ASGPR on the surface $[58,61]$. The dependence on the level of gene expression can be explained in terms of the apparent molecular size of complexes as well as the interaction with the receptors of cell surface. First, it is reported that a certain range of apparent molecular size of polyion complexes was effective in enhancing the in vitro gene expression [62, 63]. Complexation with spermine-pullulan with the same spermine introduction and molecular weights ranging from $22.8 \times 10^{3}$ to $212 \times 10^{3}$ reduced the molecular size of plasmid DNA, whereas smaller spermine-pullulan did not [58]. On the other hand, complexation with high amounts of spermine-introduced pullulan prepared at $[\mathrm{CDI}] /[\mathrm{OH}]$ ratios of 1.5 to 5.0 reduced the molecular size of plasmid DNA, whereas a lower amount of spermine-introduced pullulan did not, irrespective of the pullulan molecular weight [61]. It is possible that the compacted complex of reduced size is more readily internalized by cells, resulting in enhanced gene expression. In addition, it 
has been demonstrated from the lectin affinity for pullulan chains localizing on the complexes surface were different among spemine-pullulans used and that the complexes strongly interacted with the lectin showed a higher level of gene expression $[58,61]$. Taken together, it is likely that the optimal molecular size of complexes and the inherent affinity for the ASGPR results in effective increase of the cellular internalization, resulting in enhanced gene expression. The percentage of spermine introduced where the highest expression level was observed was different among the molecular weights of pullulan used for spermine introduction (Fig. 6B). The percent spermine introduction for the highest expression level tended to decrease with an increase in the molecular weight of pullulan. At the same N/P ratio, the number of spermine-pullulan complexed with plasmid DNA decreases with an increase in the molecular weight and percent spermine introduced of pullulan. There was an optimal molar number of the spermine-pullulan-plasmid DNA complex for enhanced gene expression at a N/P ratio (data not shown). This result experimentally indicates that a well-balanced combination of the spermine introduction percentage and molecular weight of pullulan is necessary to enhance the level of gene expression. However, the reason of the optimal number for the maximum gene expression is not clear at present.

In the present study, two types of endocytosis inhibitors were used to examine the endocytic pathway of spermine-introduced pullulan. The complexes were internalized by MSCs via both the clathrin- or raft/caveolae-dependent pathways (Fig. 7). A similar result was reported for another cell by Kanatani et al. [64]. The endocytic pathway of the spemine-introduced pullulan will be independent of the cell type. Lectin-mediated endocytosis has typically been characterized as occurring either via the clathrin- or raft/caveolae-dependent pathways, although it depends on the specific lectin involved [65]. The clathrin-mediated endocytosis of spermine-introduced pullulan could be initiated by the non-specific adsorption of cationic spermine groups to anionic proteoglycans of cell membrane, such as heparan sulfate. It has been reported that particles with a diameter less than $200 \mathrm{~nm}$ non-specifically adsorbed on the cell were internalized via the clathrin-mediated endocytosis and finally delivered to the lysosome, whereas particles of $500 \mathrm{~nm}$ in diameter entered cells via the caveolae pathway and were never observed in the lysosomal compartments [66]. Considering that the average diameter of sperminepullulan-plasmid DNA complexes was around $200 \mathrm{~nm}$, they would be more susceptible to the clathrin-dependent endocytosis. It is known that the formation of clathrin-coated vesicles occurs as the result of non-specific adsorption. The formation of calveola results from lectin-mediated endocytosis. Taken together, it is likely that the complex is internalized by both the pathways.

Similar to other cationized carriers, cell toxicity increased with an increase of complex added. However, high gene expression was observed by the sperminepullulan-plasmid DNA complex at the concentration of cell transfection (Fig. 8). This lower toxicity clearly indicates that the spermine-pullulan is a feasible gene carrier to enhance the gene expression for stem cells. 


\section{References}

1. M. F. Pittenger, A. M. Mackay, S. C. Beck, R. K. Jaiswal, R. Douglas, J. D. Mosca, M. A. Moorman, D. W. Simonetti, S. Craig and D. R. Marshak, Science 284, 143 (1999).

2. S. Makino, K. Fukuda, S. Miyoshi, F. Konishi, H. Kodama, J. Pan, M. Sano, T. Takahashi, S. Hori, H. Abe, J. Hata, A. Umezawa and S. Ogawa, J. Clin. Invest. 103, 697 (1999).

3. M. Reyes, A. Dudek, B. Jahagirdar, L. Koodie, P. H. Marker and C. M. Verfaillie, J. Clin. Invest. 109, 337 (2002).

4. C. Toma, M. F. Pittenger, K. S. Cahill, B. J. Byrne and P. D. Kessler, Circulation 105, 93 (2002).

5. J. S. Wang, D. Shum-Tim, J. Galipeau, E. Chedrawy, N. Eliopoulos and R. C. Chiu, J. Thorac. Cardiovasc. Surg. 120, 999 (2000).

6. Y. Gafni, G. Turgeman, M. Liebergal, G. Pelled, Z. Gazit and D. Gazit, Gene Ther 11, 417 (2004).

7. S. C. Chang, H. L. Chuang, Y. R. Chen, J. K. Chen, H. Y. Chung, Y. L. Lu, H. Y. Lin, C. L. Tai and J. Lou, Gene Ther. 10, 2013 (2003).

8. K. C. Cho, S. H. Kim, J. H. Jeong and T. G. Park, Macromol. Biosci. 5, 512 (2005).

9. G. Turgeman, D. D. Pittman, R. Muller, B. G. Kurkalli, S. Zhou, G. Pelled, A. Peyser, Y. Zilberman, I. K. Moutsatsos and D. Gazit, J. Gene Med. 3, 240 (2001).

10. A. A. Mangi, N. Noiseux, D. Kong, H. He, M. Rezvani, J. S. Ingwall and V. J. Dzau, Nature Med. 9, 1195 (2003).

11. H. Sato, N. Kuwashima, T. Sakaida, M. Hatano, J. E. Dusak, W. K. Fellows-Mayle, G. D. Papworth, S. C. Watkins, A. Gambotto, I. F. Pollack and H. Okada, Cancer Gene Ther. 12, 757 (2005).

12. M. Studeny, F. C. Marini, J. L. Dembinski, C. Zompetta, M. Cabreira-Hansen, B. N. Bekele, R. E. Champlin and M. Andreeff, J. Natl. Cancer Inst. 96, 1593 (2004).

13. S. C. De Smedt, J. Demeester and W. E. Hennink, Pharm. Res. 17, 113 (2000).

14. K. Ewert, N. L. Slack, A. Ahmad, H. M. Evans, A. J. Lin, C. E. Samuel and C. R. Safinya, Curr. Med. Chem. 11, 133 (2004).

15. M. C. Pedroso de Lima, S. Neves, A. Filipe, N. Duzgunes and S. Simoes, Curr. Med. Chem. 10, 1221 (2003).

16. A. Hirko, F. Tang and J. A. Hughes, Curr. Med. Chem. 10, 1185 (2003).

17. S. P. Vyas, A. Singh and V. Sihorkar, Crit. Rev. Ther. Drug Carrier Syst. 18, 1 (2001).

18. K. Kunath, T. Merdan, O. Hegener, H. Haberlein and T. Kissel, J. Gene Med. 5, 588 (2003).

19. M. Voinea, E. Dragomir, I. Manduteanu and M. Simionescu, Vasc. Pharmacol. 39, 13 (2002).

20. T. G. Kim, S. Y. Kang, J. H. Kang, M. Y. Cho, J. I. Kim, S. H. Kim and J. S. Kim, Bioconjug. Chem. 15, 326 (2004).

21. S. Kawakami, F. Yamashita, K. Nishida, J. Nakamura and M. Hashida, Crit. Rev. Ther. Drug Carrier Syst. 19, 171 (2002).

22. M. Singh and M. Ariatti, J. Control. Rel. 92, 383 (2003).

23. D. Wakebayashi, N. Nishiyama, Y. Yamasaki, K. Itaka, N. Kanayama, A. Harada, Y. Nagasaki and K. Kataoka, J. Control. Rel. 95, 653 (2004).

24. S. S. Diebold, C. Plank, M. Cotten, E. Wagner and M. Zenke, Somat. Cell Mol. Genet. 27, 65 (2002).

25. Y. Takei, A. Maruyama, A. Ferdous, Y. Nishimura, S. Kawano, K. Ikejima, S. Okumura, S. Asayama, M. Nogawa, M. Hashimoto, Y. Makino, M. Kinoshita, S. Watanabe, T. Akaike, J. J. Lemasters and N. Sato, FASEB J. 18, 699 (2004).

26. J. Stankovics, A. M. Crane, E. Andrews, C. H. Wu, G. Y. Wu and F. D. Ledley, Human Gene Ther. 5, 1095 (1994). 
27. D. Y. Kwoh, C. C. Coffin, C. P. Lollo, J. Jovenal, M. G. Banaszczyk, P. Mullen, A. Phillips, A. Amini, J. Fabrycki, R. M. Bartholomew, S. W. Brostoff and D. J. Carlo, Biochim. Biophys. Acta 1444, 171 (1999).

28. M. A. Zanta, O. Boussif, A. Adib and J. P. Behr, Bioconjug. Chem. 8, 839 (1997).

29. T. Bettinger, J. S. Remy and P. Erbacher, Bioconjug. Chem. 10, 558 (1999).

30. T. Azzam, H. Eliyahu, L. Shapira, M. Linial, Y. Barenholz and A. J. Domb, J. Med. Chem. 45, 1817 (2002).

31. T. Azzam, A. Raskin, A. Makovitzki, H. Brem, P. Vierling, M. Lineal and A. J. Domb, Macromolecules 35, 9947 (2002).

32. A. Vaheri and J. S. Pagano, Virology 27, 434 (1965).

33. T. Nagasaki, M. Hojo, A. Uno, T. Satoh, K. Koumoto, M. Mizu, K. Sakurai and S. Shinkai, Bioconjug. Chem. 15, 249 (2004).

34. T. Ishii, Y. Okahata and T. Sato, Biochim. Biophys. Acta 1514, 51 (2001).

35. G. T. Hermanson, Bioconjugate Techniques. Academic Press, San Diego, CA (1996).

36. J. Rejman, A. Bragonzi and M. Conese, Mol. Ther. 12, 468 (2005).

37. L. H. Wang, K. G. Rothberg and R. G. Anderson, J. Cell Biol. 123, 1107 (1993).

38. A. Subtil, I. Gaidarov, K. Kobylarz, M. A. Lampson, J. H. Keen and T. E. McGraw, Proc. Natl. Acad. Sci. USA 96, 6775 (1999).

39. N. Yang, Y. Huang, J. Jiang and S. J. Frank, J. Biol. Chem. 279, 20898 (2004).

40. M. Manunta, P. H. Tan, P. Sagoo, K. Kashefi and A. J. George, Nucleic Acids Res. 32, 2730 (2004).

41. F. Lampariello, Cytometry 15, 294 (1994).

42. D. J. Laird, U. H. von Andrian and A. J. Wagers, Cell 132, 612 (2008).

43. J. C. Roth, D. T. Curiel and L. Pereboeva, Gene Ther. 15, 716 (2008).

44. J. Prieto, V. Fernandez-Ruiz, M. P. Kawa, P. Sarobe and C. Qian, Gene Ther. 15, 765 (2008).

45. K. Nakamura, Y. Ito, Y. Kawano, K. Kurozumi, M. Kobune, H. Tsuda, A. Bizen, O. Honmou, Y. Niitsu and H. Hamada, Gene Ther. 11, 1155 (2004).

46. J. Bubenik, Int. J. Oncol. 18, 475 (2001).

47. A. Ribas, Curr. Gene Ther. 5, 619 (2005).

48. N. Kimelman, G. Pelled, G. A. Helm, J. Huard, E. M. Schwarz and D. Gazit, Tissue Eng. 13, 1135 (2007).

49. R. Kuroda, A. Usas, S. Kubo, K. Corsi, H. Peng, T. Rose, J. Cummins, F. H. Fu and J. Huard, Arthritis Rheum. 54, 433 (2006).

50. M. J. Ruitenberg, G. W. Plant, F. P. Hamers, J. Wortel, B. Blits, P. A. Dijkhuizen, W. H. Gispen, G. J. Boer and J. Verhaagen, J. Neurosci. 23, 7045 (2003).

51. M. S. Penn and A. A. Mangi, Circ. Res. 102, 1471 (2008).

52. T. Okasora, J. I. Jo and Y. Tabata, Gene Ther. 15, 524 (2008).

53. J. Jo, N. Nagaya, Y. Miyahara, M. Kataoka, M. Harada-Shiba, K. Kangawa and Y. Tabata, Tissue Eng. 13, 313 (2007).

54. B. A. Clements, V. Incani, C. Kucharski, A. Lavasanifar, B. Ritchie and H. Uludag, Biomaterials 28, 4693 (2007).

55. L. L. Farrell, J. Pepin, C. Kucharski, X. Lin, Z. Xu and H. Uludag, Eur. J. Pharm. Biopharm. 65, 388 (2007).

56. G. P. Tang, Z. Yang and J. Zhou, J. Biomater. Sci. Polymer Edn 17, 461 (2006).

57. H. Hosseinkhani, T. Aoyama, S. Yamamoto, O. Ogawa and Y. Tabata, Pharm. Res. 19, 1471 (2002).

58. J. Jo, T. Ikai, A. Okazaki, K. Nagane, M. Yamamoto, Y. Hirano and Y. Tabata, J. Biomater. Sci. Polymer Edn 18, 883 (2007). 
59. T. Tanaka, Y. Fujishima, S. Hanano and Y. Kaneo, Int. J. Pharm. 286, 9 (2004).

60. Y. Kaneo, T. Tanaka, T. Nakano and Y. Yamaguchi, J. Control. Rel. 70, 365 (2001).

61. J. Jo, T. Ikai, A. Okazaki, M. Yamamoto, Y. Hirano and Y. Tabata, J. Control. Rel. 118, 389 (2007).

62. M. Nishikawa and L. Huang, Human Gene Ther. 12, 861 (2001).

63. X. Zhou and L. Huang, Biochim. Biophys. Acta 1189, 195 (1994).

64. I. Kanatani, T. Ikai, A. Okazaki, J. Jo, M. Yamamoto, M. Imamura, A. Kanematsu, S. Yamamoto, N. Ito, O. Ogawa and Y. Tabata, J. Control. Rel. 116, 75 (2006).

65. J. Ochieng, V. Furtak and P. Lukyanov, Glycoconj. J. 19, 527 (2004).

66. J. Rejman, V. Oberle, I. S. Zuhorn and D. Hoekstra, Biochem. J. 377, 159 (2004). 
Copyright of Journal of Biomaterials Science -- Polymer Edition is the property of VSP International Science Publishers and its content may not be copied or emailed to multiple sites or posted to a listserv without the copyright holder's express written permission. However, users may print, download, or email articles for individual use. 